\title{
COMMENTARY
}

\section{The concept of risk and the value of novel markers of acute kidney injury}

\author{
Claudio Ronco*1 and Zaccaria Ricci \\ See related research by Kashani et al., http://ccforum.com/content/17/1/R25
}

\begin{abstract}
Kashani and colleagues studied two novel markers, insulin-like growth factor-binding protein 7 and tissue inhibitor of metalloproteinases-2, in the urine of patients at high risk of acute kidney injury (AKI). They validated these markers in a separate large multicenter study and compared them with known markers of AKI such as neutrophil gelatinase-associated lipocalin and kidney injury molecule-1. Insulin-like growth factor-binding protein 7 and tissue inhibitor of metalloproteinases-2 performed better than other known markers and their combination provided additional information. These markers could be useful in clinical practice to uncover silent episodes of AKI or to make an early identification of patients at risk. Ultimately they could help to detect and possibly prevent episodes of acute injury to the kidney, sometimes referred to as kidney attack.
\end{abstract}

Although acute kidney injury (AKI) is extremely common - with an incidence of about 2,100 per million population [1], similar to that of acute myocardial infarction - the condition remains difficult to treat and prognosis is poor. Indeed, early mortality associated with some forms of AKI is greater than that associated with acute myocardial infarction despite available supportive therapy such as dialysis or hemofiltration [2]. AKI, or kidney attack, should thus be considered every bit the medical emergency that we think of heart attack [3].

For this reason, the Kidney Disease: Improving Global Outcomes AKI guideline begins not with patients already with AKI but with patients at high risk of the disease [4]. Unlike myocardial infarction, kidney attack is usually

\footnotetext{
*Correspondence: cronco@goldnet.it

'Department of Nephrology, Dialysis and Transplantation, International Renal Research Institute (IRRIV), San Bortolo Hospital, viale Rodolfi 37, 36100 Vicenza, Italy Full list of author information is available at the end of the article
}

silent without signs and symptoms that guide risk assessment. A number of susceptibilities (for example, advanced age, underlying chronic disease) and exposures (for example, sepsis, radio-contrast) for AKI have been identified but there is no reliable way for a clinician to use this information to establish a clear risk profile. By contrast, a patient with pre-existing diabetes and hypercholesterolemia who presents with crushing substernal chest pain is undoubtedly at high risk for myocardial infarction. The concept of renal angina has been put forth [5], but this has been defined on the basis of small changes in renal function in patients already deemed to be at high risk. By definition, then, moderate-risk patients can only have renal angina when they manifest changes in renal function, often when kidney damage has already occurred and when it may be too late to apply treatments to preserve renal function. Furthermore, recent studies have highlighted the possible occurrence of subclinical AKI where the diagnosis cannot be made with classic criteria [6].

If patients could only tell us that their kidneys hurt then front-line clinicians could stratify patients who were most likely to develop AKI and do this at a time when interventions (such as stopping nephrotoxins) would be most likely to be effective. Furthermore, and again analogous with myocardial infarction, a tool for risk stratification would tell us which patients to monitor more closely, not with telemetry but instead with careful measurement of urine volume and serum creatinine.

In a provocative paper by Kashani and colleagues, the concentration of two novel markers - insulin-like growth factor-binding protein 7 and tissue inhibitor of metalloproteinases- 2 - was found to be increased in the urine of patients at high risk of AKI from a variety of etiologies [7]. The authors then validated these markers in a separate large multicenter study and compared them with known markers of AKI such as neutrophil gelatinaseassociated lipocalin and kidney injury marker-1. Not only did each marker perform better than other known markers, but their combination provided additional information, at least in some patients. These performance characteristics are clearly adequate for clinical use. For 
example, compared with the lowest third, patients manifesting these new markers at concentrations in the middle third had a threefold increase in risk while the third with the highest levels had a 10-fold increase. These markers therefore appear to be the pain signal that is missing in this silent disease.

An intriguing implication of this study is that, because both of these new markers can be upregulated in response to a wide range of noxious stimuli, they have the potential to be a nonspecific alarm raised by the renal tubules in response to stress. Detecting this alarm will permit several things to happen, including appropriate triage of patients, more intensive monitoring, and perhaps early involvement from specialists in nephrology and critical care who can promptly evaluate these patients while they are still in the golden hours of this disease prior to irreversible damage to the kidneys.

Finally, as new therapies for AKI are being evaluated in the next few years, the use of biomarkers to help select which patients should be enrolled in trials will be an enormous advantage over current study designs [8].

In conclusion, every single insult to the kidney is potentially dangerous and deleterious for the clinical outcome and future progression of chronic kidney disease. Because early diagnosis and thus related interventions appear possible today thanks to the use of new biomarkers, we should echo the World Kidney Day 2013 claim to 'Stop Kidney Attack'.

Abbreviations

AKI, acute kidney injury.

\section{Competing interests}

CR received honoraria for conferences from Alere, Abbvie, and Astute. ZR declares that he has no competing interests.

\section{Author details}

'Department of Nephrology, Dialysis and Transplantation, International Renal Research Institute (IRRIV), San Bortolo Hospital, viale Rodolfi 37, 36100 Vicenza, Italy. ${ }^{2}$ Department of Pediatric Intensive Care, Ospedale Bambino Gesù, Via S. Onofrio 1, 00165 Roma, Italy.

Published: 13 February 2013

\section{References}

1. Ali T, Khan I, Simpson W, Prescott G, Townend J, Smith W, Macleod A: Incidence and outcomes in acute kidney injury: a comprehensive population-based study. J Am Soc Nephrol 2007, 18:1292-1298.

2. Uchino S, Kellum JA, Bellomo R, Doig GS, Morimatsu H, Morgera S, Schetz M, Tan I, Bouman C, Macedo E, Gibney N, Tolwani A, Ronco C; Beginning and Ending Supportive Therapy for the Kidney (BEST Kidney) Investigators: Acute renal failure in critically ill patients: a multinational, multicenter study. JAMA 2005, 294:813-818.

3. Kellum JA, Bellomo R, Ronco C: Kidney attack. JAMA 2012, 307:2265-2266

4. Kidney Disease: Improving Global Outcomes: Clinical practice guideline for acute kidney injury. Kidney Int Supp/ 2012, 2:89-115.

5. Goldstein SL, Chawla LS: Renal angina. Clin J Am Soc Nephrol 2010, 5:943-949.

6. Ronco C, Kellum JA, Haase M: Subclinical AKI is still AKI. Crit Care 2012, 16:313.

7. Kashani K, Al-Khafaji A, Ardiles T, Artigas A, Bagshaw SM, Bell M, Bihorac A, Birkhahn R, Cely CM, Chawla LS, Davison DL, Feldkamp T, Forni LG, Gong MNG, Gunnerson KJ, Haase M, Hackett J, Honore PM, Hoste EAJ, JoannesBoyau O, Joannidis M, Kim P, Koyner JL, Laskowitz DT, Lissauer ME, Marx G, McCullough PA, Mullaney S, Ostermann M, Rimmele R, et al.: Discovery and validation of cell cycle arrest biomarkers in human acute kidney injury. Crit Care 2013, 17:R25.

8. Palevsky PM, Molitoris BA, Okusa MD, Levin A, Waikar SS, Wald R, Chertow GM, Murray PT, Parikh CR, Shaw AD, Go AS, Faubel SG, Kellum JA, Chinchilli VM, Liu KD, Cheung AK, Weisbord SD, Chawla LS, Kaufman JS, Devarajan P, Toto RM, Hsu CY, Greene T, Mehta RL, Stokes JB, Thompson AM, Thompson BT, Westenfelder CS, Tumlin JA, Warnock DG, et al.: Design of clinical trials in acute kidney injury: report from an NIDDK workshop on trial methodology. Clin J Am Soc Nephrol 2012, 7:844-850.

doi:10.1186/cc12488

Cite this article as: Ronco C, Ricci Z: The concept of risk and the value of novel markers of acute kidney injury. Critical Care 2013, 17:117. 